Es ist uns möglich, nun die Frage von $B$ a bes zu beantworten, der sagte ${ }^{1}$ ): "In diesem, wie in ähnlichen Fällen, entsteht die Frage, warum der Mikroorganismus, welcher die Eigenschaften eines kurzen Streptokokken besitzt, sich eben im Leberparenchym und in den Nieren angehäuft bat. Wir kennen ja zahlreiche Fälle von ähnlicher, durch Streptokokken erzeugter Septicämie, in welchen die Leber wenig verändert ist, wäbrend die Nieren häufig eine Kokkeninvasion aufweisen, was ja in der Eunction dieses Organes seine Erklärung findet. In diesem Falle könnten wir nun annehmen, dass die Streptokokken durch die Vena portae . . . in die Leber eingedrungen sind. - Aber eben hier, wo die Darmschleimbaut wenig verändert angetroffen wurde, ist die Ursache dieser Invasion weniger klar, als in anderen Fällen."

Die capillare Gallenstase ist hier eben nothwendig, um die Leber als den Hauptsitz der Infection zu charakterisiren, denn, gleich wie in den secernirenden Nieren bei Retentio urinae, bäufen sich die Bakterien im Leberparenchym bei Gallenstase auf, was bei offenen Gallengängen nicht statt hat.

Ist die Gallenstase eine capillare, event. eine allgemeine, so sprechen wir von acuter Leberatrophie; ist sie dagegen eine grobe, wie bei Infectionen, so erhalten wir den Staunngsicterus.

Der Gallengangskatarrh kann auf- oder absteigend sein.

3.

\title{
Erwiderung, betreffend die ,Aetiologie und Genese der hyalinen Thrombosen" (dieses Archiv. Bd. 138. S. 221)
}

\author{
von Dr. Holschewnik off, \\ Prosector am Marine-Hospital zu Kronstadt, Russland.
}

Nach Durchlesen der obengenannten Abhandlung sehe ich mich genöthigt, so weit sie mich anlangt, Folgendes zu entgegnen:

Dr. Pick führt mit Bezugnahme auf meine Untersucbung "Ueber hyaline Degeneration von Hirngefässen" (dieses Archiv. Bd. 112. S. 552) leider nicht meinen Wortlaut an, sondern begnügt sich mit einer ungenauen Wiedergabe des Sinnes. Nach seiner Darstellung (S. 254) bätte ich die Hyalinmassen nach Weigert'scher Färbung (bezw. mit Alauncarminvorfärbung) mit intensiv violetten, mitunter weniger dunklen, punktförmigen Massen besetzt gesehen, die vor der Färbung nicht sichtbar gewesen seien. Nirgend in meiner Arbeit habe ich von solchen Pünktchen, bezw. Tröpfchen an Byalinmassen gesprochen, sondern ich fand sie stets ausserbalb der sichtlicb unveränderten Capillarwände, in engem Zusammenhang mit denselben (S. 554, 558, 565 und 566 meiner Abhandlung). Diese "Ausschwitzung" von feinsten Tröpfchen an der äusseren Wand der Capillaren, sowie die un-

1) Babes, dieses Archiv. Bd. 136. Hft. 1. 
gleiche Grösse der Tröpfchen und ihre absolute Homogeneität, sogar bei Untersuchung mit starkem Immersionssystem (auch nach Weigert'scher Färbung), geben mir auch jetzt noch die Berechtigung, sie als junge Hyalinmassen anzusehen, und es liegt für mich durchaus kein Grund vor, hier Kugelbakterien zu vermuthen, wie Dr. Pick andeutet; seine ungenaue Wiedergabe meiner Worte bönnte den Leser in der That auf diesen Gedanken bringen.

Ferner bat mieh befremdet, dass Dr. Pick eine Analogie zwischen seinem infectiösen Falle und meinem rein chronischen Prozesse findet, bei dem die heerdförmige Erkrankung des Gehirns in ganz evidentem Zusammenhange mit der circumseripten Veränderung der Capillarwandungen stand, obne etwaige Reizerscheinungen zu zeigen, wo demnach auch keine Rede von irgend welehen Mikroorganismen sein kann.

Mikroskopische Präparate, die alles von mir oben Gesagte bestimmt bestätigen, besitzt ausser mir auch Herr Professor v. Recklinghausen.

\section{An die Herren Mitarbeiter,}

die Grösse der Abhandlungen und die Tafeln betreffend.

Vom Jahre 1879 an ist dieses Archiv erheblich erweitert worden, um den Anforderungen der Herren Mitarbeiter, sowobl in Bezug auf den zu vergebenden Raum, als auch in Bezug auf die Beschleunigung der Publication, nach Möglichkeit zu entsprechen. Dabei ist jedoch im Voraus (dieses Archiv. 1878. Bd. 74. S. 554) darauf hingewiesen worden, dass die früheren Bodingungen für die Aufnahme von Manuseripten und für die Ausstattung mit Tafeln aufrecht gehalten werden müssten. Trotz dieser Mahnung sah ich mich schon im Jahre 1881 (dieses Archiv. Bd. 87. S. 199) genöthigt, wiederholt anf die Nothwendigkeit einer sparsameren Inanspruchnabme der von dem Verleger geforderten Aufwendungen binzuweisen. Ich that dies, indem ich in ausführlicher Weise die Verbältnisse einer Zeitschrift mit festem A bonnementspreis auseinandersetzte.

Eine Zeit lang bat sich eine gewisse Wirkung dieser Ansprache bemerkbar gemacht. Aber in letzter Zeit sind die Ansprüche mit jedem Jahr wieder gewachsen, so sehr, dass schliesslich eine Häufung der Manuscripte entstanden ist, die natürlich mit einer empfindlichen Verzögerung in der Schnelligkeit der Publication verbunden ist. Der Verleger ist auf mein Ersuchen so entgegenkommend gewesen, dass er sich bereit erklärt hat, ein Supplementheft einzuscbieben, um wieder einigen Raum zu schaffen. Dieses Supplementheft ( $z$ Bd. 138) wird demnächst ausgegeben werden, und wenn die dadurch geschaffene Hülfe nicht genügt, dürfte vielleicht noch ein zwoites derartiges Heft folgen.

Aber wir bitten die Herren Mitarbeiter, diesen Vorgang als eine Ausnahmemaassregel ansehen und als Norw für die Zukunft die fräheren Be- 